\title{
Why are women still earning less than men in medicine?
}

\author{
n Cite as: CMAJ 2018 May 28;190:E664-5. doi: 10.1503/cmaj.109-5576
}

Posted on cmajnews.com on May 9, 2018.

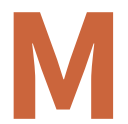

edicine has a major gender wage gap, and recent data suggest practice styles, specialty choices and discrimination all factor into the discrepancy.

Women currently make up $41 \%$ of practising physicians in Canada, but only a small minority of top-billing doctors. In 2016, the Ontario government released data that showed 506 doctors billed the province more than $\$ 1$ million in the previous year; only $8 \%$ were women. Likewise, in British Columbia, women made up less than $10 \%$ of doctors who billed more than $\$ 1$ million.

South of the border, the story is much the same. Last year, a study of the annual incomes of American physicians found that female doctors made US\$86000 less on average than their male peers. That gap has grown since 2000-2004, when the difference was US\$38000.

Multiple factors contribute to the gender gap, says Dr. Gigi Osler, president-elect of the Canadian Medical Association (CMA). "Women generally work fewer hours than men per week. Women aren't as well represented in the higher-billing specialties. Women might see fewer patients per day because they're spending more time with their patients."

The number of women in family medicine has skyrocketed in recent decades, but other specialities haven't seen the same growth. In 2017, $45 \%$ of family doctors in Canada were women, compared to $39.6 \%$ of other medical specialists and $28.4 \%$ of surgical specialists, according to CMA.

At the same time, the pay gap between family doctors and other specialists has widened. Dr. Charissa Patricelli, a family doctor in Vancouver, worries the growing proportion of women in family medicine

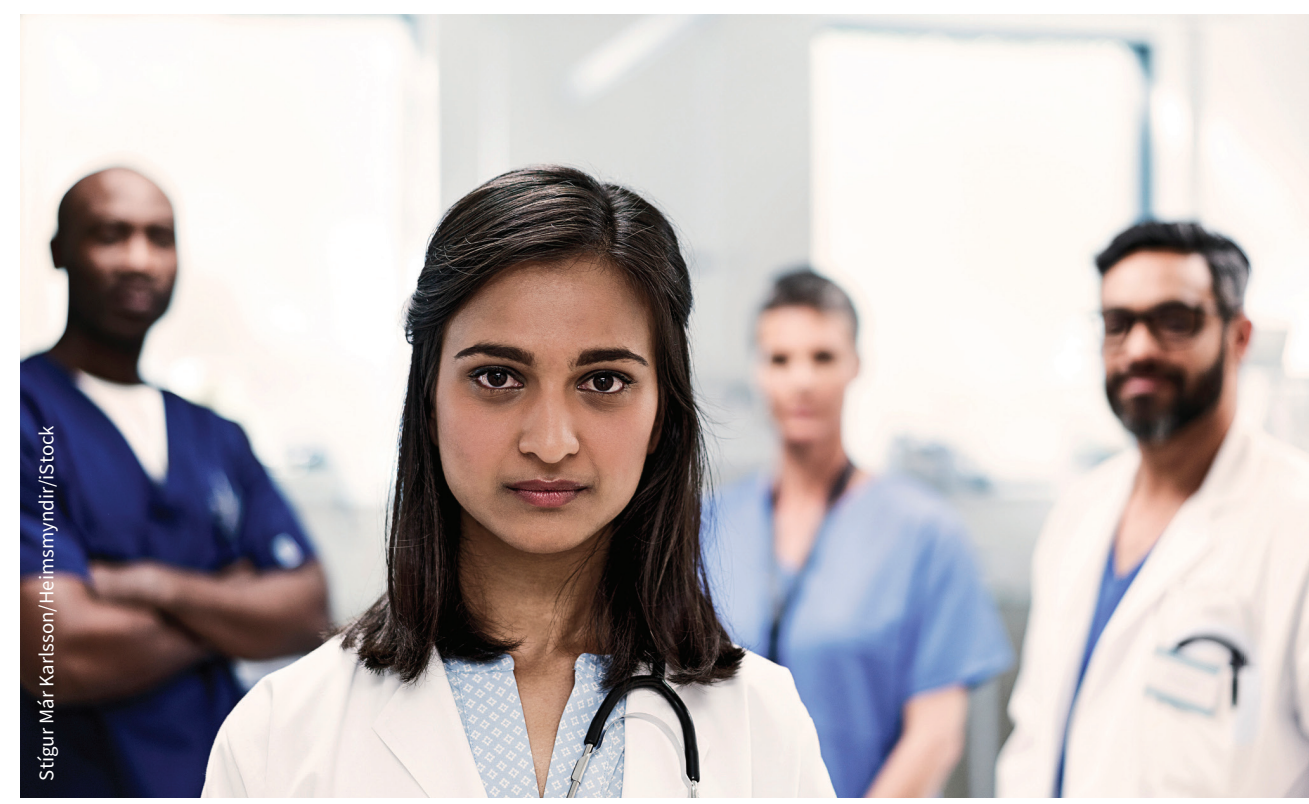

Discrimination appears to be one factor in the earnings gap between male and female doctors.

has made it easier for governments to reduce remuneration for family doctors. "Family medicine is becoming a more female profession and society doesn't value the contribution of women as much as men," she says.

The specialty gender divide isn't narrowing, either; 168 women ranked a surgical specialty as their first choice in the 2017 residency match, compared to 186 in 2010, according to the Canadian Resident Matching Service (CaRMS). Meanwhile, 618 women ranked family medicine first last year, in contrast to 352 men.

Osler says women are dissuaded from applying to surgical specialties because "the schedule is unpredictable; it's not family friendly."

However, women who rank a surgical specialty as their top choice are also less likely to be accepted into a surgical program than their male peers. Last year, only $62 \%$ of women matched to their first-choice surgical specialty, compared to $72 \%$ of men. "There's something going on there," says Dr. Susan Phillips, a professor of family medicine and public health sciences at Queen's University, in Kingston, Ont.

Crunching the CaRMS data since 2010, in all but one year, men have had higher acceptance rates into surgery than women.

Dr. Lesley Barron, a surgeon in Georgetown, Ont., thinks discrimination is at play. "Programs are worried about maternity leave in addition to all the usual gender bias," including the perception that women are less competent, she says. "Surgical programs are largely run by men and, in my experience, men prefer to work with men."

Dr. Jeremy Grushka, program director of general surgery at McGill University in Montreal, says the residency program has 
had more women than men many times in recent years, and gender is never a factor. However, considering the CaRMS data, he says, "it's possible there are still some oldway-of-thinking biases." For example, in media and training scenarios, "surgeons are often presented as being an authoritarian male figure."

The gender wage gap isn't only related to specialty choice. "It's both interspecialty and intra-specialty," says Barron. For one, women work slightly fewer hours than men, on average. In a recent CMA survey of 7000 doctors, women reported working an average 48 hours a week, while men worked an average 52 hours. Patricelli attributes this difference to the fact that "women continue to do the majority of childcare, whether in a low or high socioeconomic group."

Women may also be billing less than men because studies show they spend more time with their patients, and thus bill less frequently under fee-for-service models. (Fee-for-service still represents the largest portion of most physicians' pay in Canada.) Since female doctors tend to be younger, "it's hard to know how much is related to gender, and how much is generational," says Osler.
Despite the complex barriers, Dr. Nadia Alam, president-elect of the Ontario Medical Association, is hopeful for more wage equality. She thinks the slow but steady growth of women at negotiating tables between provincial governments and doctors will result in more effective bargaining.

"Women don't fight the same way men do. Women use persuasion as opposed to trying to beat their opponents in a debate," she says. "I think we're going to see more women fighting for better pay in the coming years."

Wendy Glauser, Toronto, Ont 